\title{
CLEAR CELL ODONTOGENIC CARCINOMA OF THE MAXILLA
}

\author{
Zahide Mine Yazici', Ozgur Mete ${ }^{2}$, Zubeyde Elmalı', İbrahim Sayin ${ }^{1}$, Rasim Yilmazer', Fatma Tulin Kayhan ${ }^{1}$
}

Bakırköy Dr. Sadi Konuk Training and Research Hospital, Department of Otorhinolaryngology Istanbul, Turkey ${ }^{1}$; Istanbul University, Istanbul Faculty of Medicine, Department of Pathology, Istanbul, Turkey²

Summary: Clear cell odontogenic carcinoma (CCOC) is a rare odontogenic tumor associated with aggressive clinical behavior, metastasis and low survival. We report a case of CCOC affecting the maxilla of 62 year-old woman. It was first described as a clinicopathological entity in 1985 and to date only 67 cases were described in the English literature. We are understanding of the behavior of this carcinomas was depend on limited case reports. For these reason we found important to report this case of CCOC in the maxilla.

Key words: Clear cell odontogenic carcinoma; Histopathology; Treatment

\section{Introduction}

Clear cell odontogenic carcinomas (CCOCs) are rare, aggressive tumours that occur most frequently in the anterior region of the mandible. CCOCs affect primarily older individuals (50-70 years of age) and are more prevalent among females (8). In this article, we report a case of CCOC in the maxilla of a 62-year-old woman.

CCOCs were formerly called clear cell ameloblastomas or clear cell odontogenic tumours and were considered benign tumours in the 1992 World Health Organization (WHO) classification (3). Because these tumours have an aggressive and destructive growth capacity and may metastasise to distant organs and lymph nodes, the 2005 WHO classification listed them as malignant tumours characterised by sheets and islands of vacuolated and clear cells (3).

\section{Case Presentation}

A 62-year-old woman was referred to our clinic with the complaint of painless swelling of the upper jaw that had persisted for 10 years and had increased overtly in size in the previous 7 months. Physical examination revealed a tumour located in the hard palate and extending to the soft palate. The patient's medical history, including her family history, was unremarkable. Computed tomography (CT) scans of the paranasal sinuses revealed a $5 \times 5-\mathrm{cm}$ tumour mass originating in the right lateral maxilla. The mass exhibited a destructive growth pattern on the hard palate, with extension into the soft palate and subcutaneous tissues (Fig. 1). Both upper cervical jugular zones were unremarkable, except for a dominant lymph node with a maximum diameter of $0.7 \mathrm{~cm}$. Abdominal ultrasound and chest radiographs revealed no other tumour mass. An incisional biopsy revealed a tumour composed of fibrous and hyaline stroma with islands of epithelial cells containing clear to faintly eosinophilic cytoplasm. The tumour cells exhibited well-demarcated cell membranes and some islands showed variably peripheral cell palisades. No obvious mitosis or necrosis was observed. The tumour cells tested positive for anti-pan-cytokeratin (Fig. 2), epithelial membrane antigen, and cytokeratins 14 and 19, and negative for anti-S100 protein, HMB-45, vimentin, desmin, smooth-muscle actin (Fig. 3), CD10, chromogranin, thyroid transcription factor-1 (TTF-1), thyroglobulin, glial fibrillary acidic protein (GFAP), and calponin. Following the diagnostic assessment

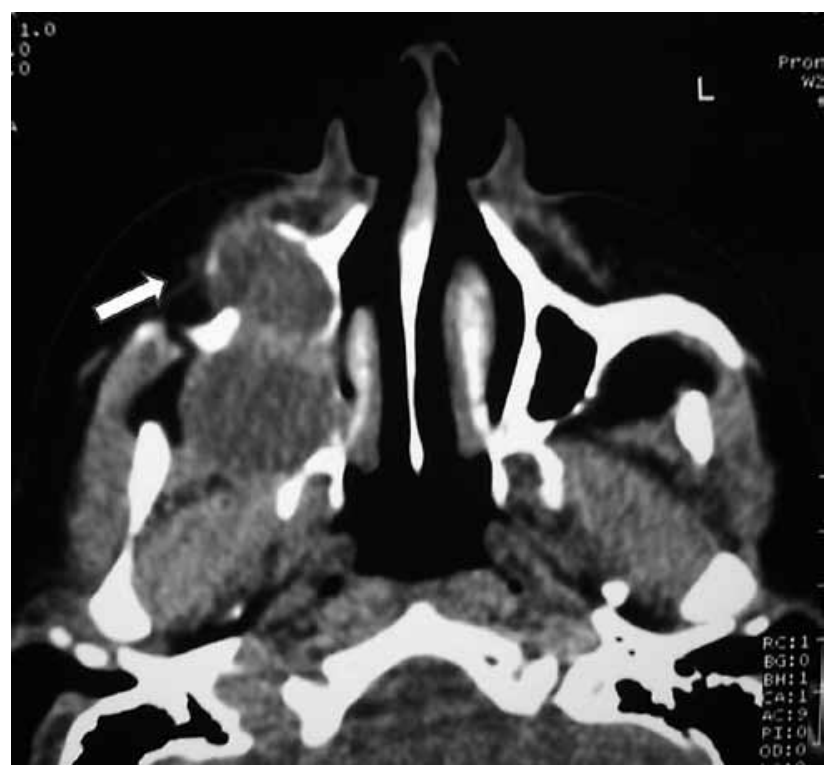

Fig. 1: CT scan white arrow showing an enhancing mass which destroying its wall. 


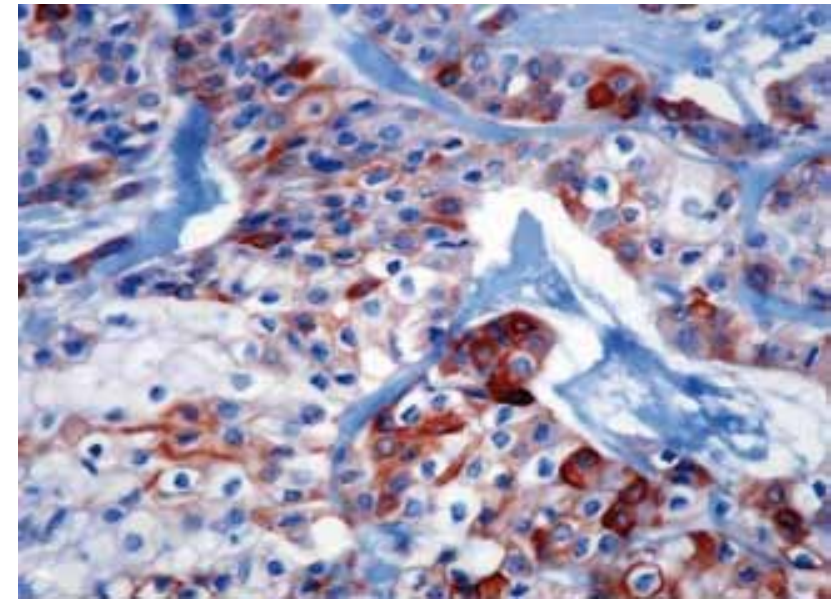

Fig. 2: Tumor cells were positive for anti-pancytokeratin. (Original magnification, $\times 40$ ).

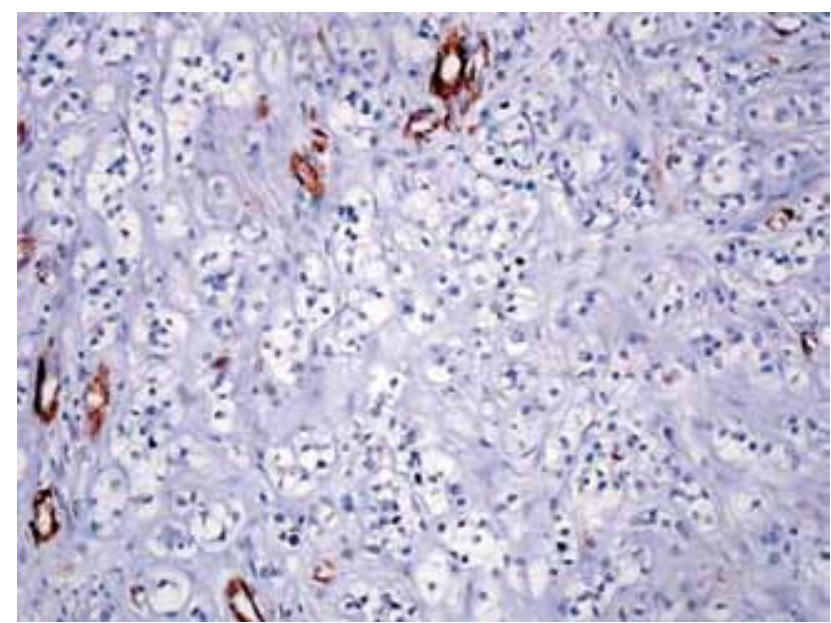

Fig. 3: Tumor cells were negative for anti-smooth muscle actin. (Original magnification, $\times 20$ ).

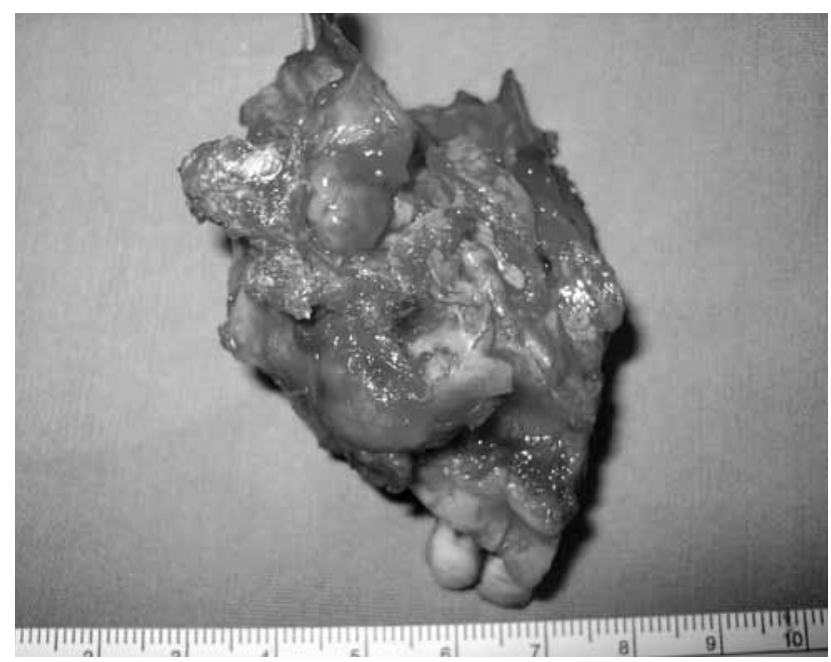

Fig. 4: Postoperative surgical specimen. of the incisional biopsy, the patient underwent a maxillectomy and the surgical specimen was subjected to detailed histopathological examination (Fig. 4). The surgical margins were negative. The patient has remained asymptomatic and was last seen in follow-up 2 years after surgery.

\section{Discussion}

Clear cell trans-differentiation or change is not restricted to a certain tumour type. Because many other primary and metastatic tumours may exhibit clear cell changes, the diagnosis of CCOC can be very difficult in the absence of a well-constructed immunohistochemical panel (3). The differential diagnosis of a carcinoma with clear cell changes may include primary clear cell carcinoma of the salivary glands, perivascular epithelioid cell tumour (PEComa), metastatic tumours such as renal cell, adrenal cortical, parathyroid, and thyroid carcinomas, and other adenocarcinomas with clear cell changes. The presence of palisading supports the odontogenic origin of such lesions, especially when accompanied by inductive fibrohyalinisation of the stroma.

Clinically, CCOCs are rare tumours of the jaw showing a strong female predilection and tending to occur in older adults; the mean age at diagnosis is approximately 60 years (8). The majority of cases have occurred in the anterior region of the mandible; the maxilla is rarely involved (7). Most patients complain of lumps or tooth abnormalities (4).

The aetiology of this neoplasm remains poorly understood. No previous report has explained the occurrence of $\mathrm{CCOCs}$ in relation to potential precursory lesions, such as odontogenic rests, residual cysts, or odontogenic keratocysts (4). Based on published data and our clinical experience, the diagnosis of CCOC depends on the exclusion of other tumours. Histological, immunohistochemical, and ultrastructural analyses of neoplasm features are thus important.

CCOCs may be aggressive and are capable of local recurrence, as well as regional and distant metastasis. Such tumours should be treated by wide en bloc resection with negative margins and patients should receive long-term follow-up (6). In the presence of clinical and/or radiographic evidence of nodal metastases, neck dissection should also be performed. Level 1 lymph nodes, which are the most common nodal sites for lymphatic metastasis, should be given special attention (5).

\section{References}

1. August M, Faquin W, Troulis M, Kaban L. Clear cell odontogenic carcinoma: Evaluation of reported cases. Journal of Oral Maxillofacial Surgery. 2003; 61(5):580-6.

2. Avninder S, Rakheja D, Bhatnagar A. Clear cell odontogenic carcinoma: a diagnostic and therapeutic dilemma. World Journal of Surgical Oncology 2006; 4:91.

3. Barned L, Everson JW, Reichart P, Sidransky D., eds. World Health Organization Classification of Tumours. Pathology and Genetics of Head and Neck Tumours, IARC Press: Lyon 2005.

4. Dahiya S, Kumar R, Sarkar C, Ralte M, Sharma MC. Clear cell odontogenic carcinoma: a diagnostic dilemma. Pathology Oncology Research. 2002; 8(4):283-5. 
5. Gasparini G, Boniello R, Moro A, Federico F, Castri F, Pelo S. Unusual clear cell tumors of the jaws - clinical and histopathological considerations: a case report. Journal of Medical Case Reports. 2008; 2:290.

6. Maiorano E, Altini M, Viale G, Piattelli A, Favia G. Clear Cell Odontogenic Carcinoma; Report of Two Cases and Review of the Literature. American Journal of Clinical Pathology 2001; 116:107-114.
7. Werle H, Blake FA, Reichelt U, Schmelzle R, Heiland M. Clear-cell odontogenic carcinoma: a new case and long-term follow-up of an old case, and review of the literature. Journal of Oral Maxillofacial Surgery. 2009 Jun; 67(6):1342-8.

8. Zhang J, Liu L, Pan J, Tian X, Tan J, Zhou J, Duan Y. Clear cell odontogenic carcinoma: report of 6 cases and review of the literature. Med. Oncol 2010 published online.

Received: 06/01/2011

Accepted in revised form: 26/04/2011

\section{Corresponding Author:}

Dr. Z. Mine Yazici, Bakırköy Dr. Sadi Konuk Eğitim ve Araştırma Hastanesi, Zuhuratbaba Mah. Tevfik Sağlam Cad. No. 11, Bakırköy, Istanbul, Türkiye; e-mail: minealmaz@yahoo.com 